\title{
0 Processo de Aquisição de Tecnologia pela Indústria Petroquímica Brasileira
}

\author{
Carlos A. Hemais, Henrique M. Barros, Mirela T. Pastorini \\ Grupode Gestão Tecnológica, IMAUFR
}

Resumo: Um dos setores industriais brasileiros mais dinâmicos, a indústria petroquímica, está localizada em três pólos (Camaçari, São Paulo e Triunfo) e hoje representa cerca de $2 \%$ do PIB do país. O estabelecimento dessa indústria no Brasil ocorreu há menos de 30 anos, por iniciativa governamental, através da adoção de um modelo societário de empresa chamado modelo tripartite. Neste modelo 1/3 do capital era proveniente da Petroquisa, 1/3 de sócio privado nacional e 1/3 de sócio estrangeiro, geralmente fornecedor da tecnologia, que era explorada pela formação de joint-ventures. Apesar de já ser uma indústria consolidada e de grande potencial de exportação, a petroquímica ainda é bastante dependente tecnologicamente de fontes exógenas e essa dependência não parece que será eliminada a curto prazo. O presente trabalho examina o processo de aquisição tecnológica por parte da indústria petroquímica brasileira, dando ênfase ao uso de joint-ventures como a forma escolhida para obtenção da tecnologia.

Palavras-chave: Indústria petroquímica brasileira, transferência de tecnologia, joint-ventures, pólos petroquímicos.

\section{The Process of Technology Acquisition in the Brazilian Petrochemical Industry}

\begin{abstract}
One of the most dynamic industrial sectors in Brazil, the petrochemical industry is located in three complexes (Camaçari, São Paulo and Triunfo), and today it represents around 2\% of the Brazilian GNP. This industry was established in the country nearly 30 years ago as a governmental initiative, when the government adopted a tripartite model of a commercial society. In this model, 1/3 of the capital belonged to Petroquisa, $1 / 3$ belonged to a Brazilian partner and $1 / 3$ belonged to a foreign partner, usually the supplier of the technology through a joint venture. In spite of the fact that this industry is consolidated and has a large potential of exports, the petrochemical industry is still technologically dependent upon exogenous sources. Moreover, it seems that this dependency will not be eliminated in the near future. The present paper examines the process of technological acquisition by the Brazilian petrochemical industry, especially the use of joint ventures as the way chosen to obtain technology.
\end{abstract}

Keywords: Brazilian petrochemical industry, technology transfer, joint-ventures, petrochemical complexes.

\section{Introdução}

A indústria petroquímica é considerada um dos setores industriais brasileiros mais importantes. A partir da instalação no país de três pólos petroquímicos (São Paulo, Camaçari e Triunfo), desenvolveu-se de forma ordenada uma indústria que hoje se constitui em uma das mais ativas do país. Seu crescimento ocorreu em ritmo vigoroso na década de setenta e início da década de oitenta, enfrentou com ímpeto todo o início da recessão econômica e processo inflacionário descontrolado, e tornou-se, na época, um grande fornecedor do mercado externo, contribuindo de forma destacada para a balança comercial do país.

O estabelecimento da indústria petroquímica brasileira ocorreu pela adoção do modelo tripartite, através do qual as joint-ventures formadas eram constituídas, geralmente, de 1/3 de capital proveniente

Autor para correspondência: Carlos A. Hemais, Grupo de Gestão Tecnológica, IMA/UFRJ, C.P. 68545, CEP: 21945-970, Rio de Janeiro, RJ. E-mail: hemais@ima.ufrj.br 
da companhia estatal brasileira de petróleo, Petrobrás, através de sua subsidiária Petroquisa, $1 / 3$ de sócio privado nacional e o 1/3 restante de sócio estrangeiro, normalmente através de fornecimento de tecnologia. A formação destas joint-ventures poderia propiciar posteriormente melhores condições para a efetiva absorção e transferência tecnológicas. A opção governamental pelo modelo tripartite seguia um planejamento estratégico de dotar o país de uma forte indústria de base, na qual a petroquímica se incluía. No caso brasileiro, além do interesse pela tecnologia, estava o desejo de implantar em um pequeno espaço de tempo, uma infraestrutura que permitisse ao país ser auto-suficiente em derivados petroquímicos. Assim, não houve a preocupação inicial de criar tecnologia nacional para suprir essa indústria nascente, uma vez que era exigido curto prazo para instalação dos Pólos Petroquímicos. Com o decorrer dos anos, a formação tripartite do capital das empresas foi-se modificando. Essa modificação foi acelerada a partir do processo de privatização iniciado pelo governo brasileiro, no início da década de 90 .

O presente trabalho estuda a forma de aquisição de tecnologia pelo setor petroquímico brasileiro e tenta delinear possíveis mudanças ocorridas ao longo desses anos no que diz respeito ao processo de capacitação tecnológica.

\section{Tecnologia: importância estratégica}

Estudos já comprovaram que o desenvolvimento econômico está diretamente relacionado com a capacidade de inovação tecnológica. Conforme exposto por Matesco \& Hasenclever (1996) ${ }^{[1]}$, isso ocorre porque a inovação atua no processo produtivo, alterando a base organizacional-gerencial das empresas e acelerando, sustentando e alterando a fronteira da produção.

Além disso, os níveis de investimento das empresas em tecnologia servem como uma forma para explicar as diferenças internacionais em termos de produtividade e de conquista de mercados, de acordo com Berry \& Taggart (1994) ${ }^{[2]}$. Conforme salientam os autores, a capacidade inovativa não é, e talvez nunca venha a ser, disponível em abundância. Enquanto os mercados estão se tornando cada vez mais globais em sua natureza, o mesmo não acontece com o desenvolvimento tecnológico. As novas tecnologias e os recursos humanos preparados para produzí-las continuam restritos a poucos países.
Cada vez mais a tecnologia ganha força, o que a torna, gradativamente, indispensável às empresas. Isso se justifica pelo fato dela não apenas permitir as operações de transformação, mas também por fornecer o alicerce vital ao desenvolvimento e à sobrevivência da corporação em uma economia cada vez mais globalizada (Fusfeld, 1989) ${ }^{[3]}$. Avanços tecnológicos contribuem para as mudanças nos custos e na produtividade industrial, causando um impacto sobre as estruturas nacional e global de produção, comércio e emprego (Ohmae, 1990) ${ }^{[4]}$.

Tem-se dado um tratamento especial à tecnologia visando criar vantagens competitivas para se alcançar com êxito os resultados desejados (Stacey \& Bradford, 1990) $)^{[5]}$ e conquistar fatias de mercado. Porém, a busca intensa de oportunidades de mercado pode falhar se a empresa não estiver estruturada internamente. O que importa em estratégia é a construção e a consolidação de competências internas capazes de ativar um processo de integração (Whittington, 1993 ${ }^{[6]}$.

Assim, esse tratamento especial culmina com a integração entre as estratégias de negócios e a de tecnologia, cuja importância torna-se cada vez maior em função da internacionalização da economia e da abertura de mercado. Desenvolver um planejamento estratégico da tecnologia significa concentrar esforços para tornar possível a utilização, eficientemente, da variável tecnológica como instrumento de apoio ao cumprimento das metas e objetivos da corporação. Conforme proposto por Vasconcellos \& Saia (1993 ${ }^{[7]}$, o planejamento estratégico de tecnologia engloba não apenas a estratégia de pesquisa e desenvolvimento (P\&D); mas também as estratégias de tecnologia de manufatura e de tecnologia de informação. E essas três estratégias se interligam, formando um conjunto de decisões que são interdependentes.

Schumpeter $(1934)^{[8]}$, em sua época, já havia predito que o processo inovativo, a "destruição criativa", é vital para a manutenção da posição monopolística do primeiro entrante no mercado. Quinn (1985) ${ }^{[9]}$ afirma que a melhor forma de se inovar tecnologicamente é de maneira incremental, pluralista e descentralizada, isto é, "um caos sob controle", segundo o autor. Porter (1985 $)^{[10]}$ sugeriu que a evolução tecnológica é a força mais importante na mudança das regras da competição. O autor, também, identificou a necessidade das firmas renovarem periodicamente suas vantagens tecnológicas competitivas, já que caso isso não 
seja feito, o competidor o fará e as desalojará de seus respectivos mercados.

Dentro desse contexto, é estudado o comportamento de um dos principais setores industriais brasileiros, o setor petroquímico, quanto ao aspecto tecnológico, principalmente pelo fato de esse setor passar por uma fase de reestruturação de suas metas e reavaliação de suas estratégias após o processo de privatização iniciado no início da década de 90 . Com a saída da Petroquisa do papel de articuladora tecnológica, o setor apresentou uma desestruturação dos organismos tecnológicos das empresas, que reduziram as suas equipes e os seus dispêndios nessas atividades. Assim, a partir de então, foi iniciada uma nova fase na indústria petroquímica brasileira, caracterizada pelo corte de subsídios, fim da reserva de mercado, política industrial e de comércio exterior liberal e diminuição dos valores das tarifas de importação. Mais especificamente, esses valores, que antes variavam entre $30 \%$ e $50 \%$, passaram a zero, nos casos de eteno, propeno e benzeno; a $10 \%$ para o estireno; e a cerca de $20 \%$ para os principais produtos petroquímicos finais, ou seja, este setor ficou mais exposto à concorrência internacional (Parisi Jr., 1993) ${ }^{[11]}$.

Hoje essa indústria ocupa uma situação privilegiada no cenário industrial brasileiro, representando $2 \%$ do PIB, porém parece que pouco foi feito em se tratando de criação de unidades autônomas de P\&D e desenvolvimento autônomo de tecnologia e isto pode representar uma séria ameaça em médio prazo.

Vale lembrar, que o mecanismo utilizado para aquisição de tecnologias até a implantação no terceiro pólo foi através de joint-ventures e, portanto, é interessante frisar alguns pontos sobre o assunto.

\section{J oint-Ventures}

Do ponto de vista das multinacionais, não é sempre possível para uma firma se estabelecer em um outro país através de uma subsidiária. Isso se torna ainda mais crítico quando o outro país possui um mercado doméstico atrativo, porém com forte intervenção governamental. Sendo assim, a formação de uma joint-venture pode ser a única opção possível para a empresa ter alguma participação nesse novo mercado (Gomes-Casseres, 1989; Gilpin, 1987) ${ }^{[12,13]}$. Mowery (1989 ${ }^{[14]}$ observou que a joint-venture pode ser uma opção razoável em termos de riscos e custos, quando comparada com o investimento direto (foreign direct investment), e em termos de acesso mais rápi- do a um novo mercado, quando comparada com a exportação. Também permite um controle melhor da tecnologia do que o licenciamento.

Alguns países restringem participações totalitárias de empresas estrangeiras em seus territórios. Contudo, o fornecimento de conexões pelos parceiros locais, é uma maneira rápida de entrar em novos mercados com capital limitado e a joint-venture pode ser uma opção atrativa para se obter escala global em P\&D e em produção (Hemais, 1997 ${ }^{[15]}$. Davidson \& Mc Fetridge $(1985)^{[16]}$ observaram que o parceiro local, tendo acesso à tecnologia, pode tentar mudar os termos do empreendimento. Apesar disso, é crescente o reconhecimento de que a formação de joint-venture é uma boa opção estratégica para a firma investir, por causa da divisão de riscos e responsabilidade gerencial (Casson, 1987) ${ }^{[17]}$.

É possível detectar na literatura sobre jointventures que, em países em desenvolvimento, uma das motivações dos sócios locais para a realização de empreendimentos conjuntos com empresas estrangeiras reside no fato de se desejar a transferência tecnológica e o acesso facilitado, por parte dos sócios locais, aos melhoramentos e desenvolvimentos futuros. Entretanto, uma outra linha de pensamento se mostra contrária à anterior por achar que o sócio estrangeiro (fornecedor da tecnologia) não repassa completamente as informações necessárias, o que lhe permite participar de maneira incisiva sobre as decisões referentes ao controle do empreendimento. Em países em desenvolvimento, é comum observar a firma estrangeira fornecendo a tecnologia, enquanto os parceiros locais fornecem o aporte de capital, o conhecimento do mercado, a mão-de-obra e o suporte do governo local. Uma discussão mais detalhada sobre o assunto pode ser vista em Hemais et al (1994) $)^{[18]}$.

No caso brasileiro, além do interesse na tecnologia, estava o desejo de implantação da indústria petroquímica em um país sem tradição no setor e o sócio estrangeiro se fazia necessário pois, além de ser detentor do conhecimento tecnológico, ele possuía conhecimentos de logística, de assistência técnica, entre outros, que auxiliariam o rápido desenvolvimento dessa indústria (Silva Filho, 2000) ${ }^{[19]}$.

\section{Indústria petroquímica brasileira}

\section{Algumas características}

O setor químico é descrito por Pavitt (1984) ${ }^{[20]}$ 
como setor baseado na ciência (science based), cuja característica é ter como principal fonte de tecnologia a função $\mathrm{P} \& \mathrm{D}$. A indústria petroquímica mundial se caracteriza, desde sua origem, por elevada intensidade de capital, movimentação de grandes volumes de matérias-primas e economia de escala expressiva. Além disso, as firmas consideradas líderes do setor petroquímico adquiriram ao longo do tempo alto grau de integração da cadeia produtiva, em relação a novas etapas de processamento e a controle de fontes de matérias-primas. Essa característica permite um aumento do porte da empresa e, assim, uma elevação no faturamento, nos investimentos em P\&D e uma diminuição dos riscos da monoprodução. É interessante ressaltar que, seguindo a tendência mundial de integração, as empresas petroquímicas transnacionais com atuação no Brasil são, aqui, mais integradas e diversificadas que as próprias empresas de capital nacional. Da mesma forma, a globalização se intensificou a partir da década de oitenta e atualmente é condição necessária à estratégia de negócios. Assim, a indústria petroquímica integrada, diversificada e globalizada apresenta configurações para atuar em segmentos variados e mantém flexibilidade para acompanhar as alterações do mercado.

Ao contrário do padrão adotado na maioria dos países do mundo, a petroquímica brasileira, apesar de ser o segmento mais dinâmico da indústria química, ainda se encontra em nossos dias da mesma forma como foi implantada no início dos anos 70, isto é, com empresas de pequeno porte, monoprodutoras, não-integradas, utilizando economia de escopo e de difícil integração no processo de globalização. Talvez isso tenha sido consequiência do montante de capital necessário à implantação das unidades produtivas, uma vez que os grupos privados nacionais não detinham tal quantia na época. Segundo Silva Filho $(2000)^{[19]}$, os grupos mais atuantes de então foram incentivados pelo governo a participar dos novos empreendimentos porém não tiveram porte de capital e experiência prévia no setor. Acresce a isso o fato de os complexos petroquímicos terem sido implantados em épocas próximas, ou seja, antes mesmo de um pólo iniciar suas atividades um novo já estava sendo idealizado. Isso limitou ainda mais a participação simultânea dos grupos privados nacionais em mais de um pólo.

Conforme bem observado por Oliveira (1994) ${ }^{[21]}$, "a petroquímica brasileira, não dotada dessas ca- racterísticas estruturais, desconhece tais possibilidades: por serem suas empresas monoprodutoras, cada planta se confunde com uma "empresa"; fechá-la, portanto, significaria encerrar as atividades da própria "empresa". Como todas permanecem no mercado, todo setor passa a operar com capacidade ociosa num mercado recessivo, resultando na ineficiência relativa do conjunto".

A indústria petroquímica brasileira foi estruturada na forma de pólos petroquímicos. Foram implantados conjuntos de indústrias de primeira geração (upstream) e de segunda geração (down-stream) ao mesmo tempo, com capacidade para atender a toda demanda projetada e, dessa forma, promover a desejada substituição de importações. Essa forma de organização deu origem na Bahia e no Rio Grande do Sul às chamadas centrais de matérias-primas, manutenção, tratamento de efluentes e utilidades que, no entanto, permaneceram como indústrias de primeira geração, independentes das empresas de segunda geração. Portanto, não existia nos pólos brasileiros uma empresa responsável por unidades de vários produtos ou, no máximo, uma empresa proprietária de fábricas cobrindo toda gama de termoplásticos; e isso constitui hoje em dia um dos problema estruturais da petroquímica nacional.

Atualmente, a petroquímica mundial continua o processo de reestruturação (fusões, trocas de acionistas, parcerias) procurando superar a demanda estagnada, agravada pelo aumento de capacidades. A petroquímica brasileira, entretanto, não seguiu o mesmo caminho e o processo de privatização tem atuado timidamente no sentido de promover a reestruturação no setor, capaz de minimizar os efeitos advindos da fragilidade dessa indústria perante a abertura do mercado. Segundo Oliveira (1994) ${ }^{[21]}$, o processo de privatização, com a consequente saída do Estado do negócio de petroquímica apenas reforçou a composição das joint-ventures ou introduziu novos grupos acionários, o que pode dificultar a autonomia decisória e a reestruturação.

\section{Desenvolvimento dos pólos}

O desenvolvimento da indústria petroquímica no Brasil ocorreu quando tal indústria se estruturava mundialmente e, em função da ausência quase completa dos principais insumos (tecnologia, capital e conhecimentos de mercado), foi necessário que firmas estrangeiras participassem do processo, seja por im- 
plantação direta de fábricas e/ou pelo fornecimento de tecnologias. Além disso, o setor petroquímico brasileiro foi instituído dentro de um sistema regulatório, cuja trajetória foi caracterizada por modificações ao longo do tempo.

Com a inauguração, em 1956, da primeira refinaria no país, passou a haver a disponibilidade de frações residuais do refino de petróleo, o que permitiu o estabelecimento de um conjunto de fábricas na região de São Paulo, dentre as quais uma de polietileno (Erber \& Vermulm, 1993) ${ }^{[22]}$. No início da década de 60 foi colocada em operação a segunda refinaria, agora no Rio de Janeiro, e, nas proximidades, foi construída uma fábrica de borracha sintética, com pequena escala de produção e tecnologia adquirida da Firestone e da Goodyear. Foram feitos esforços para assimilação dessa tecnologia e para nacionalizar os serviços de engenharia e de bens de capital, conforme relata Cunha Lima (2000) ${ }^{[23]}$. Contudo, a instabilidade político-econômica do Brasil, de 1961 a 1964, estagnou o setor, assim como toda a economia do país, e, praticamente, anulou os investimentos produtivos (Erber \&Vermulm, 1993) ${ }^{[22]}$.

Desde o início, a evolução do setor petroquímico no país foi marcada por uma série de indefinições e incertezas legais e políticas. Porém, após 1964, o novo governo brasileiro deu prioridade ao desenvolvimento da indústria petroquímica e, com isso, foi promulgada uma série de medidas, para definir e estimular a participação da iniciativa privada, dentre as quais a isenção ou redução de impostos de importação sobre as matérias-primas, cujo destino fosse a viabilização de investimentos considerados essenciais na época, e sobre produtos industrializados para os equipamentos importados. Ao Estado coube as funções de planejamento, fixação de diretrizes políticas e coordenação global dos investimentos no setor, enquanto a atividade produtiva ficou a cargo da iniciativa privada (Bastos, 1989) $)^{[24]}$.

\section{Processo de implantação dos pólos}

Durante o processo de implantação da indústria petroquímica no país, vários contratos foram firmados com empresas estrangeiras; sendo que, inicialmente, tais contratos tinham como característica o fato de abrangerem "a engenharia de processo, de projeto básico, de detalhe, diligenciamento e compra de equipamentos, assistência e finalização de construção e montagem, testes de aceitação, partida e pré- operação da fábrica" (Erber \& Vermulm, 1993) ${ }^{[12]}$. Além disso, especialmente para os produtos finais (polímeros), também eram fornecidas informações advindas do produto e suas respectivas aplicações.

Bastos (1989) ${ }^{[24]}$ detectou que a tecnologia exógena tinha seu desempenho garantido pela aquisição de equipamentos, serviços e outros insumos de fontes específicas, ou seja, o fornecedor procurava restringir ao máximo as ações da indústria quanto a sua capacitação tecnológica e impunham nos contratos cláusulas de sigilo e restrições à ampliação da capacidade ou à implantação de novas unidades.

Diversos autores (Bastos, 1989 ${ }^{[24]}$; Amaro, 1985 ${ }^{[25]}$; Teixeira, $1985^{[26]}$ ) acreditam que devido ao fato de as principais preocupações iniciais terem sido voltadas para a implantação da indústria no país, não é possível detectar o estabelecimento de uma política tecnológica explícita, ou seja, o objetivo inicial limitou-se ao estabelecimento de uma indústria para atender a demanda do mercado interno.

A primeira fase de implantação dos pólos petroquímicos se caracterizaram por certa inexperiência por parte das autoridades brasileiras na negociação de cláusulas contratuais relativas à transferência de tecnologia. Eram comuns cláusula de sigilo eterno aparecerem em contratos firmados com fornecedores estrangeiros. Isto se modificou bastante a partir de 1970, quando foi criado o INPI (Instituto Nacional da Propriedade Industrial), que ficou responsável pela política governamental de propriedade industrial e por desenvolver meios através dos quais o processo de transferência de tecnologia fosse mais rápido. Isso englobaria o estabelecimento de determinados critérios de negociação (como o valor dos royalties a serem pagos) e de registro de contratos, para que, dessa forma, a empresa que fosse adquirir a tecnologia, tivesse seu poder de barganha reforçado, conforme expõe Cunha Lima (2000) ${ }^{[23]}$. De fato, isso foi constatado por Bastos (1989) ${ }^{[24]}$, que observou que tanto as restrições como o prazo para o término do sigilo, previamente estabelecidos nos contratos, diminuíram após 1975, pois o INPI passou a impedir tais cláusulas e pressionou para que as empresas nacionais desenvolvessem suas respectivas atividades tecnológicas

Outros órgãos governamentais brasileiros, que estavam ligados ao financiamento de projetos de desenvolvimento econômico e tecnológico, patrocinaram projetos visando o fortalecimento da infraestrutura 
tecnológica das empresas, tentando incrementar a competitividade das empresas brasileiras.

Também foi criada a Petrobrás Química S.A. Petroquisa, subsidiária da Petrobrás, que atuou vigorosamente no planejamento e implantação dos pólos petroquímicos. Essa subsidiária tornou possível o desenvolvimento de toda a indústria petroquímica nacional.

\section{Polo Petroquímico de São Paulo, SP}

Como parte do plano de metas para a indústria petroquímica, foi iniciado, em meados da década de 60, o projeto da Petroquímica União (PQU), com a participação de grupos privados nacionais e da Petroquisa. Além disso, o Governo tomou a decisão de garantir, via Petrobrás, o fornecimento da matéria-prima (nafta) ao pólo, o que ajudou ainda mais a impulsioná-lo.

O pólo petroquímico de São Paulo foi a primeira experiência no setor. Tentou-se aproveitar a infraestrutura já existente no estado, e criar uma central de fornecimento de matéria-prima (a PQU), que atendesse à demanda das empresas (a maioria de capital privado, nacionais e multinacionais) que já se localizavam na região. Paralelamente, grupos nacionais começaram a estabelecer joint-ventures com firmas estrangeiras, sendo que, em muitas destas, a Petroquisa teve participação, formando a composição acionária denominada de "modelo tripartite", mencionado anteriormente. Este modelo foi propagado e serviu como paradigma na constituição dos demais complexos petroquímicos no Brasil, até porque tanto as empresas estrangeiras como os financiadores estrangeiros dos futuros empreendimentos estavam exigindo a participação da Petroquisa.

\section{Pólo Petroquímico de Camaçari, BA}

Em 1970, já com um ritmo de industrialização acelerado, fez-se necessário a expansão da produção de petroquímicos e, a partir daí, foi tomada a decisão de implantar um novo pólo, com melhor infraestrutura. $\mathrm{O}$ local escolhido foi Camaçari, Bahia. Embora a região escolhida fosse afastada do centro industrial do sul do país, este pólo se justificava pois teria alguns incentivos fiscais e, além disso, estava próximo às fontes de matéria prima, uma vez que a Bahia dispunha, na época, de $80 \%$ das reservas de petróleo conhecidas.

A participação da Petroquisa como principal articulador do pólo foi de fundamental importância pois assegurava o apoio governamental e, além disso, permitia a presença de um sócio que tinha a visão de todo um conjunto e experiência, devido à implantação do pólo em São Paulo.

Teixeira (1985) ${ }^{[16]}$ observou que as tecnologias tiveram de ser selecionadas por critérios que, em sua maioria, não obedeceram a aspectos técnicos. Esses critérios estavam mais relacionados aos interesses das multinacionais. Silva Filho (2000) ${ }^{[19]}$ relatou que eram poucas as multinacionais interessadas em participar dos investimentos no país, confirmando-se que, inicialmente, os aspectos técnicos não foram relevantes no processo de seleção das tecnologias. Outro aspecto a ser ressaltado, seria a deficiência de pessoal qualificado e experiente no setor para análises técnicas mais detalhadas.

\section{Pólo Petroquímico de Triunfo, RS}

Com as metas governamentais de manter o crescimento e alcançar autonomia econômica e tecnológica para o país, através de estrutura empresarial forte, capaz de competir também com o mercado externo, foi iniciado o projeto para implantação de um terceiro pólo petroquímico. Após disputas políticas, foi decidido que o novo pólo seria na Região Sul (Triunfo - Rio Grande do Sul) que detinha, na época 20\%, do mercado nacional de produtos petroquímicos, além do fácil acesso aos principais mercados sul-americanos da Argentina, Uruguai, Paraguai e Chile.

Esse pólo, de dimensões inferiores aos demais, e inaugurado em 1982, apresentou algumas modificações em relação ao modelo original pois privilegiava o fortalecimento do capital privado nacional e o esforço para capacitação tecnológica a partir de melhor absorção das tecnologias exógenas. Isto pode ser observado nos requisitos para as empresas se instalarem, que previam programas de absorção e desenvolvimento das tecnologias.

Apesar das modificações realizadas, as fases de implantação e de operação das empresas do pólo de Triunfo ainda se mantiveram com uma ampla intervenção governamental. Houve, contudo, menor participação acionária da Petroquisa nas empresas de segunda geração, porém a central de matérias-primas (Copesul) permaneceu integralmente estatal. Procurou-se o fortalecimento dos sócios privados locais, concedendo-lhes recursos financeiros e garantindo a liderança dos projetos. Assim, os sócios estrangeiros 
deveriam efetuar a transferência efetiva de tecnologia e teriam prioridades aqueles que permitissem e contribuíssem para o desenvolvimento de capacitações tecnológicas e aumentassem, comparado com o passado, sua contribuição em termos de capital de risco (Bastos, 1989) ${ }^{[24]}$.

Com o mesmo intuito, Teixeira (1985) ${ }^{[26]}$ mostrou que foram utilizados novos critérios para seleção das firmas de engenharia, de forma a permitir a Copesul não apenas construir e operar as unidades, mas maximizar o uso de serviços locais e ainda dominar o conhecimento para construção de plantas similares. Assim, as firmas estrangeiras deveriam participar também do programa de transferência de tecnologia, além de fornecer a engenharia de processo, básica e serviços, necessários à construção das plantas. Ocorreram, ainda, treinamentos de pessoal das empresas brasileiras pelas licenciadoras de tecnologia, assim como técnicos advindos dessas fornecedoras vieram auxiliar no processo de implantação e partida da fábrica, porém tudo restrito a nível operacional.

\section{Início dos novos tempos}

Em princípios dos anos 80, o governo brasileiro promoveu medidas políticas para melhorar a capacitação tecnológica do setor, tais como fortalecimento do capital privado nacional e tentativa de criação de mecanismos para absorção de tecnologia importada, entre outras, conforme explicado anteriormente. No entanto, em função da segunda crise do petróleo de 1979 e do agravamento da crise econômica brasileira, alguns projetos foram ameaçados. Teixeira (1985) ${ }^{[26]}$ sugere que alguns resultados foram alcançados em termos de transferência de tecnologia, principalmente nas negociações de contratos, mas que foram menores do que o esperado devido às crises econômicas do período.

Após a implantação do Pólo de Triunfo, foi interrompido um processo onde um novo pólo tinha seu planejamento iniciado antes mesmo do anterior ter sido finalizado. Por muitos anos, indústria petroquímica teve o mercado interno cativo, promovido pela reserva do mercado e conseqüente proibição de importação. Ao mesmo tempo, com as subvenções patrocinadas pelo governo brasileiro, o produto final tinha preço altamente competitivo em termos de mercado internacional e fez com que a opção de exportação fosse uma alternativa muito utilizada para momentos de crise no mercado interno, como a ocorrida na época. O segundo choque do petróleo e a política de ajuste recessivo motivaram uma crise tal que fez com que a indústria petroquímica se deparasse, pela primeira vez, com a situação de ser obrigada a exportar devido à queda no consumo interno. Pesquisa realizada na época demonstrou que, em determinado período, havia empresas que chegavam a exportar 75\% de sua produção (Hemais et al, 1989) ${ }^{[27]}$. Se, por um lado, a alternativa de exportação apontava um caminho viável para a produção, por outro lado a dependência tão pesada do mercado externo poderia criar uma situação irreal e de extrema instabilidade, uma vez que a concorrência no exterior começava a ser violenta.

Nesse processo, o aparato regulatório se fez presente através do estabelecimento de preços ao longo da cadeia produtiva e da articulação com a Interbrás, antiga trading da Petrobrás, que assumiu os estoques existentes para vendê-los no exterior. Foram elaboradas metas, oriundas de pressões políticas, que atendessem a todos os interesses, ou seja, a expansão dos pólos de Camaçari e Triunfo, o desgargalamento do pólo de São Paulo e a implantação de um pólo no Rio de Janeiro para absorver o gás natural proveniente da Bacia de Campos. Como conseqüência, muitos projetos não foram adiante.

$\mathrm{O}$ aparato regulatório que sustentava a indústria petroquímica nacional começou, então, a mostrar os primeiros sinais de desestruturação. Além disso, o controle de preços realizado fez com que a distância entre os preços nacionais e internacionais crescesse gradativamente.

Em 1988, foi realizada uma reforma tributária que reduziu as tarifas médias de importação. Essa reforma não afetou, inicialmente, a estrutura do setor, mas deixou delineado o que estava por vir e que certamente poderia provocar o desmoronamento de um dos pilares que sustentavam a indústria petroquímica brasileira, ou seja, a proteção de mercado.

Contudo, apesar dos primeiros sinais de deterioração da estrutura reguladora do setor, no decorrer da década de 80 , as empresas do pólo de Camaçari organizaram um programa de pesquisas de interesse comum e procuraram utilizar o Centro de Pesquisas e Desenvolvimento (CEPED), o qual era mantido pelo estado da Bahia. Entretanto, as atividades não prosperaram. Paralelamente, a Petroquisa decidiu criar um centro de pesquisas destinado a desenvolver tecnologia, 
em forma de consórcio, para atender às necessidades das empresas do Sistema Petroquisa, com investimentos da ordem de US\$35 milhões, gerando 180 empregos diretos, dentre os quais $2 / 3$ de pessoal de nível superior. O centro seria formado pela fusão do efetivo tecnológico da Gerência Técnica da Petroquisa (GETEC) e do Departamento de Polímeros do Centro de Pesquisas Leopoldo Miguez de Mello, da Petrobrás. O empreendimento foi penalizado em função do Programa de Desestatização do Setor Petroquímico. O projeto foi interrompido e o esqueleto do prédio do CENTEP se encontra abandonado na Cidade Universitária da Ilha do Fundão, no Rio de Janeiro.

Em 1990, o novo governo brasileiro instalou uma política de caráter liberal e a regulação do setor petroquímico sofreu sua grande crise, chegando-se ao fim do aparato governamental regulatório. As vendas internas, no início da década de 90, sofreram quedas e foram ainda mais agravadas pela concretização de alguns empreendimentos, tais como a duplicação da Copene, as ampliações da Copesul e da PQU, além do aumento do número de empresas produtoras de termoplásticos ao redor dos pólos.

Em 1993 foram observados alguns sinais de recuperação do setor, mas uma nova etapa favorável só foi observada em meados de 1994 com a retomada do mercado internacional e a recuperação da economia nacional, com o novo plano econômico do país, o Plano Real.

\section{Pólo do Rio de J aneiro - futuro}

Como mencionado anteriormente, os planos para a criação de um pólo no Rio de Janeiro surgiram juntamente a interesses de expansão dos pólos de Camaçari e São Paulo. O complexo petroquímico seria instalado em Itaguaí, com a finalidade de absorver o gás natural proveniente de Campos. Este teria menor participação do Estado e o modelo tripartite não deveria mais ser adotado na formação das empresas. No que se refere à tecnologia, contudo, seria mantida a política anteriormente adotada, istoé, aquisição de tecnologia estrangeira, através de joint ventures, sem maior preocupação para o processo de sua absorção. Entretanto, o projeto da instalação de um novo pólo petroquímico no Rio de Janeiro foi suspenso e adiado por alguns anos.

Em meados da décade de 90, o complexo petroquímico do Rio de Janeiro voltou ao noticiário, apresentando uma nova realidade em sua concepção, sendo denominado, agora, de pólo gás-químico. $\mathrm{Na}$ verdade, o chamado pólo será uma fábrica de polietileno ligada a uma unidade de pirólise de gás natural, ou seja, um sistema mais sintético que dos outros pólos existentes no Brasil onde se utiliza a nafta para a geração de vários subprodutos.

O pólo terá uma capacidade de 540 mil toneladas/ ano de polietileno, sendo que $70 \%$ da produção será destinada para abastecer o mercado nacional e o restante 30\% será destinado para exportação (Bouch, 2000).

A mudança realmente significativa e que torna o processo distinto dos demais pólos existentes é o modelo empresarial: o projeto pertence majoritariamente à iniciativa privada, através da associação dos grupos Unipar e Suzano (66,6\% do capital), mais a participação da Petroquisa (16,7\%) e do BNDESpar $(16,7 \%)$, que criaram uma empresa especificamente para explorar a nova atividade - a Rio-Polímeros. Não há mais disputas políticas, proteção de preços e vantagens oferecidas pelos órgãos governamentais. Existe, agora, a iniciativa privada e financiadores externos, sendo necessário, portanto, um projeto competitivo para possíveis disputas, oriundas de uma economia de caráter liberal, e capaz de atender as exigências dos financiadores (Bouch, 2000) ${ }^{[28]}$.

Entretanto, a capacitação tecnológica do país parece não ter mudado. A tecnologia será novamente proveniente de fornecedores externos, ressaltando, no entanto, uma nova mentalidade e objetivo, com uma maior experiência nas negociações.

Para a unidade de polimerização, o processo de seleção de tecnologia é convencional e bem mais complexo que o da unidade de pirólise. Na pirólise o produto de interesse gerado é o eteno, com características bem definidas. Os polietilenos por sua vez, têm características dependentes do processo empregado que dão origem a produtos de qualidades e propriedades distintas influenciando nas aplicações e assim diretamente no mercado de interesse.

A Rio Polímeros analisou todas as tecnologias que estão disponíveis no mercado mundial para licenciamento e decidiu que a tecnologia de fase gasosa é a mais adequada ao mercado brasileiro, pela diversidade e qualidade de tipos de polietileno que produz (Bouch, 2000) ${ }^{[28]}$. Entendimentos havidos com a Univation (associação tecnológica da Union Carbide com a Exxon), que vai fornecer a tecnologia parece que não foram afetados, após a compra da Union Carbide pela Dow Chemical. 
"Foram analisadas tecnologias de fornecedores externos para todos os tipos de polietilenos. A escolha foi uma decisão técnica mas com um grande nível estratégico, passando diretamente pelo mercado que se quer atingir, para assim definir o tipo de produto ou possíveis combinações" (Bouch, 2000) ${ }^{[28]}$.

Há uma tendência mundial, comprovada em análises de mercado, pelo polietileno de alta densidade e polietileno linear em substituição ao polietileno de baixa densidade. Outro fator a ser considerado seria a ampliação de plantas brasileiras, já participantes do mercado, e a entrada da Dow na Argentina como concorrentes do mercado. O fato da poderosa multinacional Dow Chemical se estabelecer na Argentina e as regras de livre comércio do Mercossul não são fatores ameaçadores para a Rio Polímeros, já que a nova fábrica brasileira de polietileno estará localizado mais próximo do grande mercado da América do Sul (Rio de Janeiro e São Paulo) e terá um produto de melhor preço, uma vez que utiliza matéria-prima mais barata (eteno a partir de gás natural).

Tecnicamente foram feitas análises convencionais de cada tecnologia lembrando que os licenciadores são empresas conceituadas, com experiência nas etapas do processo, como engenharia básica e detalhamento, facilitando, assim, a aquisição de financiamentos externos pela confiabilidade do projeto.

Em síntese, embora inaugurando nova fase no planejamento da indústria petroquímica brasileira, o novo "pólo" do Rio de Janeiro segue os anteriores no que se refere à aquisição de tecnologias exógenas. É de se ressaltar, porém, que o modelo empresarial é distinto, sem interferência do Estado, e, segundo Bouch $(2000)^{[28]}$, "com uma grande dose de estratégia e uma maior experiência no que se refere aos contratos que incluem treinamentos, acompanhamentos e acesso a possíveis melhorias realizadas pelo fornecedor".

Diante desse contexto, novos investimentos parecem estar por vir, não apenas próximo à fábrica de polietileno, mas também para o desenvolvimento de um novo pólo gás-químico em São Paulo, que se encontra em fase de análise de viabilidade técnica para o empreendimento e seria desenvolvida também pela iniciativa privada, contando com o abastecimento de gás natural oriundo da Bolívia.

\section{Balanço das atividades}

A opção por joint-ventures parece que foi acertada no sentido de criar uma indústria de base não exis- tente no país, em um prazo relativamente curto. Isto foi possível devido ao interesse que o mercado brasileiro despertou em algumas empresas multinacionais, tanto pelo seu tamanho, como pelo processo de intenso crescimento econômico pelo qual o país passava na época. Acresce o fato de que, através da joint-venture, os riscos seriam divididos com o governo, através da Petroquisa.

Do ponto de vista das multinacionais, ao mesmo tempo em que dividiam os riscos da iniciativa com o governo brasileiro, esses fornecedores estrangeiros de tecnologia garantiam sua participação no novo mercado e protegiam o controle da tecnologia em um ambiente de negócios caracterizado pela forte intervenção estatal.

A experiência cumulativa adquirida com a instalação dos pólos petroquímicos brasileiros foi muito significativa, mesmo que não englobasse todos os insumos tecnológicos. Sem dúvida, a maior evolução relativa é sentida quando se observa a participação nacional no suprimento de insumos tecnológicos na implantação do pólo da Bahia e no de São Paulo. Isto pode ser sentido quando se compara o processo de planejamento, implementação e de operação dos três pólos, que se mostram bastante distintos e apresentam, claramente, os ganhos acumulados pela curva de aprendizagem ao longo do tempo.

O domínio de parte da trajetória tecnológica acabou levando muitas empresas ao desenvolvimento de otimizações e desgargalamentos, dentre outros, que possibilitaram tanto uma queda no consumo de energia como o aumento da capacidade nominal das empresas.

O acúmulo progressivo de conhecimento técnico resultou em progressiva institucionalização das atividades tecnológicas no decorrer da década de 80 . Durante esse período, os produtores de termoplásticos procuraram se adaptar à demanda e realizaram aperfeiçoamentos de produtos, desenvolveram novos grades, novas aplicações e estruturas de assistência técnica aos clientes. Ao final da década, grande parte das empresas tinha seu centro especializado em $P \& D$ ou realizava essas atividades em outros laboratórios, porém em níveis ainda modestos.

A tentativa de realizar atividades conjuntas de P\&D parece ter fracassado, mas ao longo dos anos a Petroquisa procurou se empenhar para que a trajetória tecnológica do setor petroquímico pudesse ser desenvolvida com êxito. A Gerência Técnica da 
Petroquisa, dentro de seu papel de articulador tecnológico do setor, sempre se preocupou inclusive, em acompanhar os dispêndios tecnológicos praticados pelas empresas do Sistema Petroquisa e interceder no assunto, quando necessário. As despesas com P\&D do Sistema Petroquisa cresceram aproximadamente 4 vezes no período de 1985 a 1989 , passando de cerca de US\$ 6,5 milhões para US $\$ 24,8$ milhões. Porém, cabe lembrar que tais dispêndios estão muito longe dos praticados pelas principais empresas multinacionais atuantes no setor.

Por ocasião do primeiro pólo petroquímico, o de São Paulo, a prioridade de alocação de recursos governamentais era para importação de tecnologia e engenharia de detalhamento. Por ocasião da implantação do pólo do Rio Grande do Sul, esse enfoque variou para maior ênfase às atividades de $\mathrm{P} \& \mathrm{D}$, com a finalidade de absorção da tecnologia. $\mathrm{O}$ esperado era que, a longo prazo, as empresas fossem capazes de controlar seus processos de desgargalamentos da produção e desenvolverem suas próprias inovações tecnológicas, quando o mercado assim o exigisse. Isso, porém, ainda não está operando plenamente.

Antes da deterioração do aparato regulatório, parece ter sido satisfatória a política tecnológica adotada; levando-se em conta as variáveis restritivas, a Petroquisa, juntamente com o INPI, BNDE e FINEP, procurou fazer com que as empresas, pertencentes ao Sistema, internalizassem as atividades tecnológicas. Contudo, Bastos (1989) ${ }^{[24]}$ detectou, através da análise de vários contratos de joint-ventures, que "não há nada nos contratos de tecnologia que caracterize melhores condições de transferência quando seu fornecedor é também acionista da empresa receptora". Isto também foi enfatizado por Brito (2001) ${ }^{[29]}$, quando relata que o modelo tripartite, quando o sócio estrangeiro fornecia a tecnologia, foi um dificultador para o crescimento tecnológico das empresas petroquímicas, que recebiam uma "caixa preta" sem qualquer abertura sobre a tecnologia a ser praticada, já que era de interesse do sócio manter uma dependência tecnológica do licenciador/acionista da empresa. Além disso, as empresas não dispunham de equipe capacitada para a realização de um programa de absorção tecnológica.

\section{Conclusões}

Do ponto de vista do país, embora o governo tenha lucrado com a criação de todo um setor industri- al bastante dinâmico, só houve absorção parcial da tecnologia e o país, ainda hoje, é dependente de fontes externas a cada processo de renovação ou duplicação de seu parque industrial. As tão propaladas transferência de tecnologia e o acesso às inovações parecem que se frustraram. Um balanço dos prós e contras, contudo, mostram que a experiência foi positiva e os possíveis efeitos negativos podem ainda ser corrigidos.

Atualmente, parece não existir uma política que busque a absorção tecnológica. Isso pode dificultar a internalização das atividades capazes de fornecer, a longo prazo, uma certa autonomia quanto aos fatores exógenos e, dessa forma, limitar outros investimentos; até porque o percentual do investimento destinado a tecnologia cresceu bastante desde a década de setenta (fase inicial de implantação dos pólos).

A abertura do mercado está promovendo uma busca maior de empreendimentos competitivos; isso pode ser observado com a implantação do futuro pólo gas-químico do Rio de Janeiro. Talvez essa competitividade estimule a busca pelo conhecimento da tecnologia adquirida. Contudo, é uma previsão contestada por profissionais da área, já que o futuro pólo continua apresentando características como monoprodução, ausência de integração e pequena escala, que dificultam altos investimentos em P\&D e, conseqüentemente, a efetiva absorção tecnológica.

\section{Agradecimentos}

Os autores agradecem ao CNPq pelo auxílio recebido para a pesquisa.

\section{Referências Bibliográficas}

1. Matesco, V.R. \& Hasenclever; L. "Indicadores de esforço tecnológico: comparações e implicações", Anais do XIX Simpósio de Gestão da Inovação Tecnológica, São Paulo (1996).

2. Berry, M.M. \& Taggart, J.H. "Managing technology and innovation: a review”, R\&D Management, 34 (4), 341-353 (1994).

3. Fusfeld, A.R. "Formulating strategies to meet the global challenges of the 1990s", International Journal of Technology Management, 4, 601-612 (1989).

4. Ohmae; K. "The borderless world: power and strategy in the interlinked economy", Harper Collins, New York (1990). 
5. Stacey, G.S.\& Bradford, W.A. "A structured approach to corporate technology strategy, International Journal of Technology Management, 5, 389-407 (1990).

6. Whittington, R. "What is strategy - and does it matter?", Routledge, London (1993).

7. Vasconcellos, E. \& Saia, J.R. "Integração entre P\&D e estratégia da empresa: o caso Polialden", Revista de Administração, 28 (3), Julho/Setembro, 62-72 (1993).

8. Schumpeter, J.A. "The theory of economic development", Harvard University Press, Cambridge, M.A (1934).

9. Quinn, J.B. "The management of innovation: controlled chaos", Harvard Business Review, May-June, 7384 (1985).

10. Porter; M.E. "Competitive advantage", The Free Press, New York (1985).

11. Parisi Jr., C. "Economias de escala e P\&D na petroquímica brasileira", Revista de Administração, 28 (4), Outubro/Dezembro, 15-26 (1993).

12. Gomes-Casseres, B. "Joint-ventures in the face of global competition", Sloan Management Review, 30 (3), 17-26 (1989).

13. Gilpin, R. "The political economy of international relations", Princeton, Princeton University Press (1987).

14. Mowery, D.C. "Collaborative ventures between US and foreign manufacturing firms", Research Policy, 18 (1), 19-32 (1989).

15. Hemais, C.A. "Overview - Model of international transfer of technology: a theoretical approach", Technology Management, 3 (3), July, 1-15 (1997).

16. Davidson, W.H. \& McFetridge, D.G. "Key characteristics in choice of international technology transfer mode", Journal of International Business Studies, 16, Summer, 5-21 (1985).

17. Casson, M. "The firm and the market: studies on multinational enterprise and the scope of the firm", Basil Blackwell, Oxford (1987).
18. Hemais; C.A.; Wensley, R. \& Whittington, R "Market entry strategies used by British industry in the process of commercialisation of technology" 'in Yamin, M.; Burton, F. \& Cross, A. (eds.) The Changing European Environment, vol.2, p.835-865, University of Manchester Press, Manchester, UK . (1994).

19. Silva Filho, A.P. Comunicação pessoal, IMA/UFRJ, Rio de Janeiro (2000).

20. Pavitt, K. "Sectoral patterns of technical change: towards a taxonomy and a theory", Research Policy, 13, 343-373 (1984).

21. Oliveira; J.C. "Firma e quase-firma no setor industrial: o caso da petroquímica brasileira", Tese de Doutorado, Instituto de Economia Industrial, UFRJ (1994).

22. Erber, F.S. \& Vermulm; R. "Ajuste estrutural e estratégias empresariais", IPEA: 144, Rio de Janeiro (1993).

23. Cunha Lima; L.C. O. Comunicação pessoal, IMA/ UFRJ, Rio de Janeiro (2000).

24. Bastos; V.D. "A questão tecnológica nas joint-ventures petroquímicas brasileiras", Tese de Mestrado, Instituto de Economia Industrial, UFRJ, Rio de Janeiro (1989).

25. Amaro; M.N “Transferência de tecnologia via formação de joint-ventures nos países em desenvolvimento: Estudo de caso na petroquímica brasileira", Tese de Mestrado, Instituto de Ciências Humanas, UnB, Brasília . (1985).

26. Teixeira; F. "The political economy of technological learning in the Brazilian petrochemical industry", Tese de Doutorado, University of Sussex, Brighton (1985).

27. Hemais, C.A., Christensen, C.H. \& Rocha, A. "Percepções de tecnologia brasileira e estrangeira", in Christensen, C. \& Rocha, A., Marketing de tecnologia, São Paulo, Atlas, Capítulo 3, 39-49 (1989).

28. Bouch, G.M. "O polo gás-químico do Rio de Janeiro", exposição oral, IMA/UFRJ, Rio de Janeiro (2000).

29. Brito, M. Comunicação pessoal, IMA/UFRJ, Rio de Janeiro (2001).

Recebido:14/08/01

Aprovado:15/11/01 